\title{
RANKINGS ACADÊMICOS NA EDUCAÇÃO SUPERIOR BRASILEIRA: A EMERGÊNCIA DE UM CAMPO DE ESTUDO (1995-2013)
}

\author{
Adolfo Ignacio Calderón* \\ Mariana Pfister** \\ Carlos Marshal França ${ }^{* * *}$
}

Resumo: Diante do fenômeno da expansão dos rankings acadêmicos no âmbito global, aborda-se o estado da questão sobre rankings na educação superior brasileira. A tímida produção científica localizada foi agrupada em três momentos: iniciativas pioneiras na construção de rankings (1995-1997); rankings e avaliação da educação superior (2003-2011); e, rankings no contexto da universidade de classe mundial (2008-2013). Constatou-se que, embora seja um campo de estudos emergente, o aprofundamento dos rankings acadêmicos não tem despertado o interesse dos pesquisadores das Ciências da Educação, fato que se revela na reduzida literatura acadêmica, nas lacunas existentes em termos de assuntos inexplorados, na inexistência de grupos de pesquisa sobre o tema em questão.

Palavras-chave: Educação superior. Rankings acadêmicos. Avaliação educacional.

\footnotetext{
* Pós-doutor pela Universidade de Coimbra; Doutor em Ciências Sociais pela Pontifícia Universidade Católica de São Paulo; Professor Titular do Programa de Pós-graduação em Educação da Pontifícia Universidade Católica de Campinas; Bolsista de Produtividade em Pesquisa do CNPq - Nível 2 na Pontifícia Universidade Católica de Campinas; Faculdade de Educação, Rodovia Dom Pedro I, Km 136, Pq. das Universidades, 13086-900, Campinas, São Paulo, Brasil; adolfo.calderon@pq.cnpq.br

** Graduanda em Ciências Sociais na Pontifícia Universidade Católica de Campinas; Bolsista do Programa Institucional de Bolsas de Iniciação Científica do Conselho Nacional de Desenvolvimento Científico e Tecnológico (CNPq) em dois períodos (2013-2014 e 2014-2015); Membro do Grupo de Pesquisa Gestão e Políticas Públicas em Educação da Pontifícia Universidade Católica de Campinas; Rua Clemente Regitano, 75, Vl, Esteves, 13480-633, Limeira, São Paulo, Brasil; marianapft@hotmail.com

*** Mestre em Educação pela Pontifícia Universidade Católica de Campinas; Graduado em Psicologia pela Universidade Estadual Paulista Júlio de Mesquita Filho; Professor na Pontifícia Universidade Católica de Campinas; Faculdade de Administração, Rodovia Dom Pedro I, Km 136, Pq. das Universidades, 13086900, Campinas, São Paulo, Brasil; carlos.marshal@puc-campinas.edu.br
} 


\title{
Academic rankings in brazilian higher education: the emergence of a field of study (1995-2013)
}

\begin{abstract}
Given the expansion of the academic rankings'phenomenon, on the global range, we discuss the state of the question about the rankings in brazilian higher education. The timid scientific production located was divided into three phases: pioneering initiatives in the construction of rankings (1995-1997); rankings and evaluation of the higher education (2003-2011); rankings in the context of the world-class university (2008-2013). It was found that although this is an emerging field of study, the deepening of the academic rankings has not attracted the interest of the researchers of Educational Sciences, a fact that we can see in the reduced academic literature, in the existing gaps on unexplored issues, in the lack of research groups on the topic in question.
\end{abstract}

Keywords: Higher education. Academic rankings. Educational evaluation.

\section{INTRODUÇÃO}

Nas últimas décadas, assiste-se à expansão, em âmbito global, dos mais variados tipos de rankings acadêmicos, ${ }^{1}$ internacionais, nacionais ou regionais. As Instituições de Educação Superior (IESs) passam a concorrer entre si e a ser classificadas a partir do seu desempenho em índices e indicadores promovidos pelos governos ou pelo setor privado, os quais tentam mensurar a qualidade dos serviços educacionais oferecidos (ORDORIKA; GÓMEZ, 2010).

Contextualizados na cultura da performatividade (BALL, 2002, p. 4) instaurada nos sistemas educativos, os rankings apresentam-se com inúmeras funções que lhes permitem ganhar certa legitimidade, atuando na condição de:

a) instrumentos de utilidade pública que auxiliam a tomada de decisões dos cidadãos no momento de escolher os serviços educacionais que pretendem adquirir;

b) instrumento de identificação de prestígio e diferenciação institucional no mercado educacional;

c) instrumentos concretos para a distribuição dos recursos públicos, regulação e controle da qualidade dos sistemas educativos por parte do Governo; 
d) instrumentos que munem a imprensa e os meios de comunicação de informações disseminadas na opinião pública sobre a performance das IESs.

A expansão da cultura de ranqueamento na educação superior a partir da força de grandes rankings internacionais - o Academic Ranking of World Universities (ARWU), mais conhecido como ranking da Universidade de Shangai, assim como o World University Rankings, produzido pelo suplemento Times Higher Education Suplemente (THEs) do influente jornal inglês The Times, incluindo o QS World University Rankings, da Corporação Quacquarelli Symonds (QS) e suas versões regionais, que vão da Ásia à América Latina - vêm acenando para a consolidação de um modelo de educação superior denominado modelo de Universidade Mundial do Banco Mundial ou, modelo Anglo-Saxão de universidade, o mesmo que, conforme Sguissardi (2005), encontra-se em pleno processo de implantação ao redor do mundo e no Brasil, ancorado em orientações emanadas da Organização para a Cooperação e Desenvolvimento Econômico (OCDE), da Organização das Nações Unidas para a Educação, a Ciência e a Cultura (Unesco) e do Banco Mundial (BM).

Essa realidade emergente descortina um fértil campo de estudos potencialmente promissor para o surgimento de grupos de pesquisa brasileiros especializados na compreensão da dinâmica e do funcionamento dos rankings acadêmicos, bem como das complexas redes sociais que lhes garantem sua expansão, crescimento e sustentação. Nessa perspectiva, este artigo apresenta o estado da questão sobre rankings na educação superior brasileira, tomando como referência principal a produção de artigos científicos em revistas consideradas de elevada qualidade. ${ }^{2}$ Assim, neste artigo, foi realizado um rigoroso levantamento bibliográfico com o intuito de identificar como os rankings acadêmicos têm sido abordados no âmbito acadêmico-científico brasileiro, com destaque para os temas e enfoques predominantes, apresentando-se um instigante panorama sobre a situação e a trajetória dos estudos dos rankings acadêmicos no Brasil.

Para a produção deste artigo, efetuou-se um levantamento bibliográfico com as bases de dados do Scientific Eletronic Library Online (Scielo) e do Educ@) Publicações on-line de Educação, datados até o final do ano 2013, tendo como descritores as palavras-chave "ranking", "rankings", "ranqueamento" e a combinação das palavras-chave "avaliação", "educação", "superior". Optou-se por pesquisar nesses dois bancos de dados na medida em que são as principais ferramentas que reúnem artigos publicados em revistas brasileiras consideradas de elevada qualidade acadêmico- 
-científica. O primeiro banco de dados se caracteriza por filtrar artigos produzidos em revistas das mais diversas áreas do conhecimento, enquanto o segundo concentra revistas específicas da área das Ciências da Educação.

Um levantamento inicial apontou a existência de cerca de 800 artigos capturados pelas palavras-chave mencionadas. Após a leitura dos resumos de cada um deles, selecionaram-se 22 artigos que abordaram da forma mais direta possível os fenômenos relacionados à produção e à disseminação de rankings acadêmicos no Brasil. Entre esses 22 artigos, enquadram-se trabalhos que tratam de forma empírica e aprofundada os rankings acadêmicos, bem como outros que, nas suas análises sobre a educação superior, teceram algum tipo de reflexão a respeito desse tipo de ranking.

Para apresentar a maneira como se encontra o estado da questão sobre rankings na educação superior brasileira, os artigos foram lidos integralmente, fichados, catalogados e analisados, encontrando-se aspectos comuns e divergências que permitiram agrupá-los em três grandes momentos, dentro de uma sequência histórica. O primeiro deles, marcado pelas iniciativas pioneiras na construção de ranqueamentos para as universidades brasileiras (1995-1997); o segundo momento trata do fenômeno do ranqueamento no âmbito das políticas públicas de avaliação da educação superior (2003-2011); e, o terceiro e último momento, que permite visualizar o surgimento de estudos da dinâmica dos rankings internacionais no contexto da emergência da universidade de classe mundial (2008-2013).

\section{INICIATIVAS PIONEIRAS NA CONSTRUÇÃO DE RANKINGS PARAAS UNIVERSIDADES BRASILEIRAS (1995-1997)}

Os primeiros estudos relacionados a rankings na educação superior, encontrados na literatura educacional brasileira, remontam a meados dos anos 1990 (SCHWARTZMAN, 1995; SCHWARTZMAN; OLIVEIRA JÚNIOR, 1997). Foram estudos realizados em um contexto histórico marcado pela implantação de políticas de inspiração neoliberal, em escala mundial, que repercutiram também na América Latina e no Brasil, e que resultaram em reformas do Estado de modo geral e na educação em particular (AFONSO, 1999, 2013; BARROSO, 2003, 2005).

Com o título Dificuldades e possibilidades de se construir um ranking para as universidades brasileiras, Schwartzman (1995) propõe a construção de um ranking de qualidade para 92 universidades do país. Essa proposta de ranking baseia-se na elaboração de indicadores que permitam aferir qualidade a partir das três prin- 
cipais atividades de uma universidade: pesquisa, ensino graduação e pós-graduação e extensão universitária.

Tais indicadores foram construídos por Schwartzman (1995) a partir de informações relacionadas ao perfil dos docentes das universidades, por meio das quais o autor propõe a criação de um Índice de Qualificação do Corpo Docente (IQCD), de informações obtidas com base na avaliação dos cursos de graduação efetuada, à época, pelo Guia do Estudante da Editora Abril e com base na avaliação dos cursos de pós-graduação realizada pela Capes.

Em seu trabalho, possivelmente o primeiro do gênero no país, Schwartzman (1995) indica a necessidade de melhoria da qualidade das estatísticas brasileiras e de estímulo à geração de novos dados que contribuam para a construção de sistemas de avaliação mais confiáveis. Tais propostas, segundo o autor, estariam diretamente ligadas à possibilidade de se discutir a pertinência e a qualidade dos indicadores, apontando caminhos para a melhoria das informações.

Em 1997, sob o título Ranking IPEAD/UFMG e Exame Nacional de Cursos: uma comparação, Schwartzman e Oliveira Júnior retomam a discussão do texto anteriormente citado e apontamduas formas de se avaliar a educação superior no Brasil.

A primeira delas, desenvolvida pelos próprios autores, é o Ranking IPEAD/ $\mathrm{UFMG}^{3}$ e envolve uma metodologia de avaliação de cursos de graduação testada em 1996 para os cursos de Administração, Economia e Ciências Contábeis do Estado de Minas Gerais. Essa metodologia analisa os insumos do processo de educação superior, ou seja, alunos, docentes e infraestrutura.

A segunda forma é o Exame Nacional de Cursos (ENC), o "Provão" aplicado pelo Ministério da Educação a partir de 1996 com os concluintes de cursos de graduação.

A metodologia do IPEAD/UFMG baseou-se na escolha de algumas variáveis tradicionais nos processos de avaliação, e a coleta de informações foi feita por meio de questionários enviados às instituições. As variáveis escolhidas estavam relacionadas ao perfil do corpo discente (relação candidato/vaga no vestibular, número de bolsas para alunos do curso, relação ingressantes/formandos, percentual de vagas preenchidas no vestibular e número médio de alunos por turma); à qualidade do corpo docente (número de bolsas de pesquisa, participação em comitês assessores de natureza acadêmica, titulação e regime de trabalho); e, à infraestrutura (disponibilidade de microcomputadores para alunos e professores e números de títulos na biblioteca). Essa metodologia tem como pressuposto fundamental a correlação entre quantidade/qualidade dos insumos e qualidade do processo/resultado. Assim, por exemplo, 
supõe-se que uma maior relação candidato/vaga, professores mais titulados e maior quantidade de livros na biblioteca resultam em cursos de melhor qualidade.

O Exame Nacional de Cursos (ENC), implementado pelo MEC a partir de 1996, incluiu em sua primeira edição os Cursos de Administração, Direito e Engenharia Civil. A partir dos resultados obtidos pelos alunos nesse exame, os cursos foram classificados em cinco diferentes conceitos: A, B, C, D e E.

O texto de Schwartzman e Oliveira Júnior (1997) buscava verificar eventual correlação entre os desempenhos dos Cursos de administração, com base no desempenho no ENC e no IPEAD/UFMG, esse último transformado em conceitos A, B, C, D e E. O resultado obtido foi de 0,9880 , indicando um alto grau de correlação entre as avaliações feitas pelo MEC e pelo IPEAD/UFMG.

A análise dos artigos citados parece apontar a emergência, àquela altura, de estudos que subsidiassem a construção de métodos que permitissem ranquear as universidades brasileiras, tendo como objetivo a busca de aprimoramento da qualidade no ensino superior no país.

\section{O RANQUEAMENTO NO ÂMBITO DAS POLÍTICAS PÚBLICAS DE AVALIAÇÃO DA EDUCAÇÃO SUPERIOR BRASILEIRA (2003- 2011)}

O período compreendido entre 2003 e 2011 é marcado por artigos que remetem o fenômeno do ranqueamento ao âmbito das políticas públicas de avaliação da educação superior no Brasil. Podem-se agrupar os artigos produzidos nesse período em três subgrupos. No primeiro, os artigos analisam os rankings como um fenômeno negativo, relacionado a uma dimensão mercadológica, midiática, que emerge da construção de uma política de avaliação governamental de caráter regulatório e ganha impulso a partir da criação do Exame Nacional de Cursos. No segundo subgrupo, encontra-se considerável literatura publicada a partir 2008, em que prevalecem críticas a desvirtuamentos pelos quais passou o processo de implantação do Sistema Nacional de Avaliação da Educação Superior (Sinaes). Esses trabalhos focalizam o ranqueamento como um mecanismo neutralizador da proposta inicial do Sinaes, articulada a um processo de avaliação de natureza emancipatória e formativa e não classificatória e regulatória. Por fim, no último subgrupo, enquadra-se reduzida quantidade de artigos que buscaram observar e analisar as políticas educacionais que estavam se desenhando no cenário brasileiro, compreendendo positivamente o papel dos rankings 
nesse processo, à luz da sua capacidade de gerar maior transparência e contribuir para o processo de melhoria da qualidade da educação.

Nos textos que discutem as relações entre avaliação, regulação e ranqueamento e remetem essa discussão a aspectos relacionados ao papel do Estado na formulação e implementação de políticas de educação superior, existe uma ênfase no que seus autores denominam dimensão mercadológica do ensino superior.

Souza e Oliveira (2003) discutem as transformações ocorridas no papel do Estado, nas últimas décadas, e as relações entre tais modificações e a oferta e gestão da educação. A partir de processos que envolvem a privatização de empresas estatais, a desregulamentação econômica, o acréscimo de investimentos privados e parcerias com o setor empresarial para a ampliação da oferta de serviços públicos, transforma-se o papel do Estado e sua relação com a oferta e a gestão da educação, ganhando destaque uma função de natureza mais reguladora, com ênfase em processos de avaliação do sistema, que passam a operar em uma lógica chamada pelos autores de quase mercado (um continuum de formas organizacionais, que vão do mercado puro à gestão e financiamento estatal da educação).

Para evidenciar como se concretizou no Brasil essa concepção de gestão, Souza e Oliveira (2003) apresentam as iniciativas de avaliação direcionadas à educação básica e superior implantadas no final da década de 1990. São focos de suas considerações o Sistema Nacional de Avaliação da Educação Básica (SAEB), o Exame Nacional do Ensino Médio (ENEM) e o Exame Nacional de Cursos (ENC), apresentados como avaliações de escolas, de egressos do ensino médio e de concluintes do ensino superior, respectivamente.

Embora os discursos dos defensores dessa abordagem de avaliação em larga escala a enxerguem como mecanismo indutor da qualidade, Souza e Oliveira (2003) não compartilham dessa opinião, uma vez que, segundo eles, tal abordagem tem como um de seus desdobramentos um processo de naturalização das desigualdades, legitimando valorações úteis à indução de procedimentos competitivos entre escolas e sistemas para melhorar pontuações nos rankings, definidos basicamente pelos desempenhos em instrumentos de avaliação em larga escala.

Dias Sobrinho (2004) aborda mais especificamente o campo da educação superior, estabelecendo uma vinculação da avaliação às reformas da educação superior e suas relações com o Estado. Sustenta que a avaliação tem papel não apenas técnico, mas, sobretudo, ético e político de grande importância nas transformações e reformas da educação superior e da própria sociedade, o que permitiria compreender a avaliação a partir de dois paradigmas distintos: em um deles a avaliação se desenvolve 
como controle e tem como objetivo a verificação e a medida de conformidade; no outro, a avaliação é a ação de atribuição de valor e produção de sentidos - um projeto aberto sobre o futuro.

O primeiro paradigma está vinculado a uma concepção de educação como mercadoria, com destaque para a tendência recente de enfatizar a função econômica da educação, de colocá-la, principalmente, a serviço de satisfazer as demandas do mercado de trabalho e as necessidades das empresas e dos negócios, ou seja, a serviço de interesses privados. O segundo paradigma está articulado a uma concepção de educação como bem público, envolvendo atividades necessárias, as quais devem ser compreendidas como um processo social que assegure o sentido de formação de que deve se revestir a educação.

Dias Sobrinho (2004) efetua uma crítica ácida à tendência de educação como mercadoria e, por consequência, ao papel dos rankings como escalas de avaliação características desse modelo.

Também marcados por tentativas de estabelecimento de relações entre os processos de regulação e avaliação, esta pesquisa identificou os textos de Gouveia et al. (2005), Meneghel, Robl e Silva (2006) e Rothen e Schulz (2007). Tratam-se de artigos que, publicados em anos imediatamente posteriores à edição da lei que criou o Sinaes, entendem que a sistemática de avaliação presente na proposta desse sistema permitiria superar as limitações de natureza eminentemente regulatória e classificatória das políticas de avaliação existentes até então.

Gouveia et al. (2005) elaboram estudo que analisa a trajetória das políticas de avaliação da educação superior no Brasil a partir da década de 1980. Enfatizam, em sua análise, o caráter regulatório já apontado e destacam, em particular, o papel que o Exame Nacional de Cursos teve no estímulo ao ranqueamento de instituições no Brasil e as limitações desse processo enquanto implementação de uma política de avaliação efetiva. Publicando o trabalho logo após a promulgação da lei que instituiu o Sistema Nacional de Avaliação da Educação Superior (Sinaes), os autores tinham grandes expectativas de que essa nova sistemática de avaliação recuperasse a dimensão formativa necessária a uma lógica de avaliação menos regulatória e que fortalecesse a função social da educação superior.

Meneghel, Robl e Freitas da Silva (2006) publicam estudo que busca estabelecer relações entre avaliação e regulação na educação superior. A partir de uma análise comparativa das políticas de avaliação e regulação no Brasil, na França, na Espanha, em Portugal e na Argentina, buscam evidenciar que a avaliação tem sido vista, no conjunto desses países, como forma de promover a qualidade da educação 
superior. Em todos os países analisados, aponta-se que os procedimentos de avaliação vêm se subordinando a procedimentos de supervisão, denominados pelas autoras com o termo regulação, sob responsabilidade do Estado.

A conclusão das autoras é a de que, em quase todas essas situações, a delimitação entre as fronteiras da avaliação e da regulação é, muitas vezes, tênue, não estando clara nem mesmo para os próprios agentes governamentais envolvidos nesses processos. Consideram auspicioso, entretanto, o processo de avaliação brasileira deflagrado com o Sinaes, entendido, àquela altura, como elemento que permitiria estabelecer relações mais claras e coordenadas entre esses processos, aproximando o Brasil de países com práticas de avaliação mais consolidadas.

Rothen e Schulz (2007) também discutem aspectos relacionados à implantação da proposta do Sinaes. Após traçar um breve histórico da avaliação da educação superior no Brasil, no qual destacam, particularmente, os anos imediatamente anteriores à publicação da Lei que instituiu o Sinaes, com ênfase nos mecanismos de controle governamental e de mercado, retratados pelo estímulo à competição interinstitucional representada pelo antigo "Provão" e pela divulgação de rankings dele decorrentes, os autores apresentam as principais características no então "novo" sistema de avaliação da educação superior brasileira, com destaque para o caráter sistêmico e integrado da nova legislação.

A partir de 2008, verifica-se a publicação de diversos artigos relacionados à avaliação da educação superior que abordam desdobramentos posteriores à criação do Sinaes, destacando o que pode ser chamado de desvios ou descaracterizações de seus princípios fundamentais, relacionados à ideia de uma avaliação de natureza formativa. Esses artigos (LEITE, 2008; LIMANA, 2008; BARREYRO, 2008; BRITO, 2008; POLIDORI, 2009; DIAS SOBRINHO, 2010; ROTHEN; BARREYRO, 2011) compartilham de uma visão crítica dos processos de ranqueamento de instituições de ensino superior, processos que viriam a ser estimulados por desvios de rota da proposta original do Sinaes. Ao impulsionar processos de ranqueamento, a sistemática de avaliação da educação superior no Brasil teria voltado a impelir processos de competição entre as instituições, acentuando o caráter de mercadoria associado ao ensino superior.

Leite (2008) e Limana (2008) enfatizam em seus textos a descaracterização do Sinaes, posta em evidência pela perda de importância dos processos de autoavaliação institucional, que perderam importância diante da proeminência do Enade e dos rankings produzidos com a divulgação de seus resultados. Barreyro (2008), em artigo intitulado De exames, rankings e mídia, analisa o processo de descaracterização do Sinaes, há pouco apontado, destacando o aparecimento de dois novos indicadores que se 
prestaram a propósitos midiáticos e que favoreceram um processo de ranqueamento oficial na estrutura da educação superior brasileira: o Índice Geral de Cursos (IGC) e o Conceito Preliminar de Curso (CPC). Criados por meio de Portarias Normativas, esses indicadores não responderiam apenas a questões de natureza técnica, mas estariam conduzindo, novamente, “[...] ao tempo dos rankings, das avaliações mercadológicas e simplificações midiáticas, mais próximos de uma visibilidade publicitária do que da verdade da avaliação da qualidade.” (BARREYRO, 2008, p. 867).

Brito (2008), por sua vez, efetua uma análise da evolução do Enade, desde a criação do Sinaes em 2004 até a edição do exame realizada em 2007. Seu parecer final é o de que as alterações verificadas ao longo desse período representam uma regressão, uma vez que os novos indicadores criados (IDD, CPC e IGC) pouco contribuíram, efetivamente, para o aperfeiçoamento do sistema e acabaram despertando e incentivando questões de natureza midiática ao propiciar processos de ranqueamento.

Polidori (2009) se alinha ao grupo de autores há pouco citados na crítica efetuada aos desdobramentos do Sinaes, particularmente após 2008, com a introdução de novos indicadores de qualidade no contexto da educação superior brasileira, o CPC e o IGC, já destacados anteriormente neste texto. Esses indicadores induziriam práticas objetivas de ranqueamento, permitindo classificar as melhores e as piores instituições com base em dados estanques, pontuais e que não refletiriam os princípios subjacentes à avaliação emancipatória que estava presente nos primórdios do SINAES.

Dias Sobrinho (2010) discute o conceito de qualidade na educação superior, estabelecendo relações entre os processos de avaliação da qualidade e de acreditação na educação superior. Segundo esse autor, o conceito de qualidade que teria prevalecido na educação superior tratada como mercadoria é um critério que precisa ser objetivado, quantificado, mensurado e certificado nos mesmos moldes que prevalecem na indústria moderna. Envolve, portanto, processos de padronização e homogeneização lastreados em modelos preestabelecidos e que, uma vez alcançados, conferem um selo de qualidade na oferta de um produto ou de um serviço.

Inspirado por esse pano de fundo, Dias Sobrinho (2010) critica as transformações pelas quais passou o processo de avaliação da educação superior no Brasil, a partir de 1995, particularmente, no que se refere às alterações sofridas ao longo do processo de implantação do Sinaes. As principais objeções do autor relacionam-se ao processo de crescente importância atribuída a índices de qualidade produzidos com base em indicadores estanques e à progressiva centralidade das notas do Enade como elementos aferidores de qualidade de cursos e instituições, em detrimento dos processos mais abrangentes de autoavaliação e avaliação institucional externa, presentes por 
ocasião da implementação do Sinaes. Essas modificações, ferindo os princípios norteadores que ditavam o espírito do Sinaes, culminaram em uma cultura de competitividade, eficiência e performatividade, cujos objetivos são o controle, a comparação, a hierarquização e o ranqueamento.

Rothen e Barreyro (2011) corroboram o conjunto de argumentos apresentados pelos autores já citados, no que se refere aos desdobramentos pelos quais passou o Sinaes e que acabaram por descaracterizar a sua proposta original. Chegam a comparar o Enade ao extinto Provão e concluem seu texto com a ideia central de que o segundo mandato do Presidente Luís Inácio Lula da Silva acabou por reeditar as velhas práticas neoliberais que marcaram a política educacional dos Governos Fernando Henrique Cardoso, marcada por uma lógica privatizante em relação à educação superior.

O terceiro e último subgrupo, composto por reduzido grupo de artigos, se comparado com os dois primeiros subgrupos, aborda os rankings desde uma ótica mais sistêmica, distante de um enfoque essencialmente teórico-crítico, revelando aspectos positivos do ranqueamento e a concorrência entre Instituições de Ensino Superior (IESs) (ANDRADE, 2009; DURHAM, 2010; CALDERÓN; POLTRONIERI; BORGES, 2011).

Andrade (2009) também discute o fenômeno do ranqueamento da educação superior brasileira à luz das políticas públicas, do papel do Estado e, igualmente, tomando como um de seus parâmetros principais de análise o Enade. Entretanto, de modo bastante diverso dos autores examinados anteriormente, não considera os ranqueamentos produzidos a partir dos resultados desse exame de larga escala como um fenômeno negativo, atrelado exclusivamente a um processo pejorativo de mercantilização e midiatização. A análise de Andrade (2009) busca enfatizar as possibilidades de efetiva melhoria na qualidade do ensino que podem ser induzidas por meio dos exames e dos ranqueamentos. Isso porque, para esse autor, a divulgação de rankings pode ser benéfica, na medida em que empresta maior transparência à oferta de serviços educacionais aos diversos públicos internos e externos da universidade. O impacto midiático da divulgação dos rankings, da mesma maneira, contribui para um processo de publicização de informações que são, em última análise, de interesse público.

Estabelecida, de início, essa diferença essencial entre o texto de Andrade e os textos dos dois primeiros subgrupos analisados, é necessário destacar, também, a análise de natureza técnica a que esse autor submete os exames de larga escala e os rankings que podem ser produzidos. Nesse sentido, o autor constrói uma tipologia dos rankings que permite compreender as limitações inerentes a cada um deles e, dessa maneira, extrair e filtrar as informações produzidas por eles. 
Durham (2010) efetua uma análise da política educacional brasileira durante os Governos de Fernando Henrique Cardoso, na qual, entre outros aspectos, destaca a criação de um sistema nacional de avaliação da educação como um todo e da educação superior em particular e de suas relações com a qualidade da educação. Nesse contexto, aponta como aspecto positivo a criação do Exame Nacional de Cursos (ENC), exame de larga escala semelhante ao Enade, na opinião dessa pesquisadora. A ampla divulgação dos resultados dos exames em larga escala, segundo Durham (2010), não constitui prejuízo ou ferramentas mercadológicas, mas instrumento de melhoria da qualidade da educação.

Calderón, Poltronieri e Borges (2011) discutem o papel dos rankings na educação superior brasileira, entendendo-os muito mais como políticas de Estado do que como meras políticas de um ou outro dos recentes governos brasileiros. Para tanto, efetuam uma análise do papel que os rankings desempenharam ao longo dos Governos de Fernando Henrique Cardoso e de Luís Inácio Lula da Silva. Considerados pelos autores como instrumentos de avaliação que podem ser elementos indutores da qualidade, os rankings vieram a ganhar crescente respeito e legitimidade no seio de governos com projetos políticos distintos, o que permite considerá-los parte de uma política de Estado.

\section{OS RANKINGS INTERNACIONAIS NO CONTEXTO DA EMERGÊNCIA DA UNIVERSIDADE DE CLASSE MUNDIAL (2008-2013)}

Os artigos que serão apresentados a seguir (LIMA; AZEVEDO; CATANI, 2008; LOPEZ SEGRERA, 2008; THERY, 2010; MOURA; MOURA, 2013) permitem visualizar a emergência de uma nova tendência em relação aos estudos sobre ranqueamento na educação superior. Tratam-se de análises acerca da dinâmica dos rankings internacionais no contexto da emergência da chamada universidade de classe mundial.

Lima, Azevedo e Catani (2008) propõem uma análise sobre o "Processo de Bolonha", movimento político e institucional europeu supranacional que visa à construção de um espaço europeu de educação superior. A análise dos autores enfatiza a centralidade que a discussão a respeito da qualidade ocupa nesse processo e a emergência do que denominam "Universidade Nova". Simultaneamente, examinam o impacto que essa concepção tem provocado no sistema universitário brasileiro e como as políticas públicas brasileiras têm sido reordenadas com base nessas novas lógicas. 
Para os autores, uma das características mais importantes desse reordenamento das universidades europeias está relacionada ao entendimento da avaliação como ferramenta de melhoria da qualidade nos moldes das atividades empresariais, com ênfase tecnocrática e gerencial. Esse entendimento aponta para modelos de avaliação em que predominam aspectos quantitativos, fundados na busca de estandardização e padrões de comparabilidade. Nessa lógica de avaliação de qualidade, ganham destaque na Europa as agências de avaliação externa, responsáveis, em boa medida, pela construção de indicadores que permitem a produção e a divulgação de rankings.

Lopez Segrera (2008) destaca as principais tendências e desafios da educação superior no mundo e na América Latina e Caribe: massificação; crescimento exponencial dos gastos com qualificação; aumento crescente da importância das tecnologias de informação e comunicação; crescimento da mobilidade internacional de estudantes; aceleração do incremento do processo de privatização; desvalorização profissional dos professores universitários; iniquidade de acesso; redução dos investimentos públicos; desatualização e inflexibilidade curriculares; emergências de "pseudouniversidades", marcadas exclusivamente pela preocupação com o lucro; e, a intensificação do debate sobre as chamadas universidades de classe mundial.

No âmbito dessas tendências, Lopez Segrera (2008) aponta também a importância crescente dos rankings, fenômeno cada vez mais na moda. Embora alguns deles tenham certa respeitabilidade, permanece ainda um constante debate sobre as limitações e falibilidades dessas escalas. Isso porque, segundo o autor, os rankings vêm sendo construídos com base em parâmetros próprios do modelo de universidade de classe mundial, assentado fundamentalmente na sua capacidade de produção científica, típica do universo anglo-saxão, e que privilegiam sobremaneira as chamadas ciências duras. Apesar de tais críticas aos rankings, Lopez Segrera entende que, em um mundo marcado por crescente competitividade e dominado por regras de mercado, os rankings são um fenômeno inevitável e, eventualmente, até mesmo necessários no universo acadêmico.

Thery (2010) desenvolve um estudo que poderia ser chamado de uma cartografia dos principais rankings universitários internacionais. Tomando como base as classificações de universidades a partir de quatro tradicionais rankings mundiais (Academic Ranking of Word Universities (ARWU), conhecido também como classificação de Xangai; Classificação Internacional Profissional dos Estabelecimentos de Ensino Superior, da École dês Mines de Paris; Ranking Times Higher Education (THE) e Webometrics Ranking of World's University), Thery transfere seus resultados 
sobre um mapa-múndi, procurando construir uma geografia mundial das universidades, de modo a constatar que configuração global essas classificações produziriam.

Thery (2010) analisa os principais aspectos de cada um dos rankings mencionados e a respectiva classificação de universidades a que estes conduzem em suas edições de 2008. A análise dos resultados produzidos pelos quatro rankings permite ao autor construir mapas geográficos, que revelam enormes semelhanças: todos eles concentram as "boas" ou "melhores" universidades em três regiões claramente definidas no globo, irradiadas a partir de três pontos: os Estados Unidos, a Europa e o Japão.

A conclusão de Thery (2010) induz a considerar-se com seriedade os resultados gerados pelos rankings, uma vez que, mesmo que se possa objetar que são construídos mediante metodologias diferentes e com indicadores também diferentes, existe uma regularidade inegável nos resultados aos que eles conduzem.

Finalmente, Moura e Moura (2013) apontam que o prestígio das instituições universitárias vem sendo influenciado, cada vez mais, pelas publicações dos sistemas de ranqueamentos nacionais ou internacionais. Esse prestígio, aferido por meio desses processos de ranqueamento, torna-se, gradativamente, menos dependente da tradição e vem se assentando em processos cada vez mais quantificáveis e verificáveis, por meio de procedimentos que permitem mensurar o desempenho das instituições a partir de determinados indicadores.

O levantamento efetuado pelos autores identificou dezenas de sistemas de ranqueamentos nacionais e globais atualmente. Esse processo tem como um de seus efeitos nocivos, muitas vezes, o reordenamento dos investimentos institucionais, voltando-os, prioritariamente, para o atendimento de indicadores que são contemplados pelos rankings, em detrimento de outras atividades universitárias as quais, eventualmente, seriam prioritárias no sentido de uma efetiva qualidade. Priorizam-se, dessa maneira, elementos de natureza muito mais midiáticos e que gerem retorno em melhoria da imagem da instituição.

Moura e Moura (2013) também apontam para um processo de crescente hegemonia do modelo das universidades de classe mundial, no sentido de um processo de padronização e de exportação de modelos dos países centrais.

\section{CONSIDERAÇÕES FINAIS}

O levantamento do estado da questão acerca dos rankings acadêmicos na educação brasileira permitiu identificar fatos e tendências, bem como formular hipóteses de trabalho resultantes da sua compreensão como objeto de pesquisa científica. 
Um fato que fica evidente diz respeito à existência de uma lacuna na literatura acadêmica, em termos de temas não abordados a respeito da trajetória dos rankings na educação superior no Brasil. Por exemplo, no período estudado (1995-2013), não se constatam estudos específicos sobre o tradicional ranking Melhores Faculdades, o primeiro no campo da educação superior brasileira, divulgado pela primeira vez em 1981 e editado anualmente, durante 19 anos, pela revista masculina Playboy. Da mesma forma, não existe qualquer estudo sobre o ranking promovido pelo Guia do Estudante (GE), da Editora Abril, lançado em 1988, existente até a atualidade - metade da segunda década do século XXI.

A inexistência de estudos sobre esses rankings acadêmicos ou outras iniciativas similares, que talvez possam ter sido criadas, permite inferir que o estudo dos rankings na educação superior é um tema que não tem despertado o interesse da comunidade acadêmico-científica brasileira. Essa constatação se corrobora quando se verifica que, na literatura analisada, apenas cinco artigos se debruçam, de forma específica, sobre o estudo dos rankings acadêmicos, abordando sua dinâmica e funcionamento. Os primeiros artigos, produzidos na década de 1990, foram os textos de Schwartzman (1995) e Schwartzman e Oliveira Júnior (1997), focados na criação de rankings acadêmicos no Brasil. O terceiro artigo, produzido aproximadamente 15 anos após a publicação do primeiro artigo de Schwartzman, foi o texto de Andrade (2009), em uma tentativa de sistematizar os rankings existentes à época no Brasil. O quarto e o quinto artigo foram produzidos por Thery (2010) e Moura e Moura (2013), os mesmos que mapeiam e analisam rankings acadêmicos internacionais.

Pode-se afirmar que diferentemente desses cinco artigos mencionados, dedicados especificamente ao estudo dos rankings acadêmicos, a maioria dos artigos analisados aborda os rankings acadêmicos de forma não empírica e genérica, dentro de macroanálises das políticas públicas de avaliação da educação superior ou como parte das análises das tendências da educação superior, nos âmbitos nacionais e internacionais.

A análise dessa reduzida literatura específica sobre rankings acadêmicos também permite constatar a inexistência de grupos de pesquisa que se foquem no estudo dos rankings na educação superior, uma vez que seus autores produziram esses artigos sobre os rankings, mas não avançaram no aprofundamento da temática, por meio da produção de outros artigos, nem avançaram na formação de pesquisadores (mestres e/ou doutores) sobre a temática em questão, fato que impediu a produção acadêmica de forma mais consistente.

Além de não existirem grupos de pesquisa focados no tema dos rankings acadêmicos, é possível constatar que são estudos produzidos por autores que não 
transitam no campo das Ciências da Educação existente no Brasil, nem circulam por suas principais organizações e eventos científicos. São seis autores, três, pesquisadores procedentes da área das Ciências Econômicas, Jacques Schwartzman, Márcio de Oliveira Júnior e Eduardo de Carvalho Andrade, um autor procedente da área da Geografia que elaborou mapas geográficos de universidades a partir dos resultados dos rankings, Thery, e dois coautores de um artigo: um jovem Mestre em Sociologia pela Universidade de Brasília, Bruno Azevedo Moura, que produziu um artigo em coautoria com Leides Barroso Azevedo Moura, pesquisadora da área das Ciências da Saúde.

Como se pode observar, a análise dos poucos estudos específicos sobre os rankings acadêmicos no Brasil revela que se trata de uma temática distante dos interesses dos pesquisadores do campo das Ciências da Educação; quase a totalidade da produção científica dessa área do conhecimento aborda os rankings acadêmicos, de forma genérica e abrangente, ancorada em um paradigma teórico-crítico, que alerta a respeito dos discursos ideológicos e interesses políticos e econômicos existentes por trás da expansão dos rankings, bem como questiona o projeto de sociedade que está em construção. Essa última afirmativa fica evidente se verificarmos que a maioria de autores, que questiona o ranqueamento no âmbito das políticas públicas de avaliação da educação superior brasileira (2003-2011), procede do campo das Ciências da Educação. Tratam-se de autores que ao questionar, em termos teóricos e ideológicos, os rankings acadêmicos, relegam a um segundo plano, em termos de interesses de pesquisa, o aprofundamento teórico e empírico dos rankings regionais, nacionais ou globais.

Diante dos argumentos expostos nessas conclusões, pode-se estruturar uma hipótese de trabalho, por meio da qual a pesquisa realizada permite constatar que embora seja um campo de estudo emergente, o tema dos rankings na educação superior não tem despertado o interesse da comunidade acadêmico-científica brasileira do campo das Ciências da Educação, fato que se revela na reduzida literatura acadêmica produzida sobre o tema em questão, nas lacunas existentes em termos de assuntos inexplorados no âmbito dos rankings, na inexistência de grupos de pesquisa emergentes ou consolidados, que se debrucem sobre o estudo dos rankings na educação superior.

Finalizando este artigo, convém destacar as tendências temáticas resultantes da análise da literatura científica estudada. A pesquisa realizada permite identificar três grandes momentos de publicações, dentro de uma sequência histórica. O primeiro, envolve estudos aqui denominados pioneiros, publicados na segunda metade dos anos 1990, representantes de iniciativas que propunham metodologias e indicadores que subsidiassem a construção de rankings na educação superior brasileira. Tais estudos, embora pautados na identificação de uma série de dificuldades 
que essa iniciativa envolveria, destacam, sobretudo, diversas vantagens dela decorrentes, em particular, aquelas relacionadas à melhoria na produção e divulgação de índices que permitissem avaliações mais confiáveis em relação a instituições em particular e ao sistema de educação superior como um todo. O segundo momento concentra estudos produzidos na primeira década do século XXI que evidenciam a proliferação de artigos os quais circunscrevem o fenômeno do ranqueamento à política de avaliação da educação superior implementada pelo Estado brasileiro. A quase totalidade desses estudos aborda a implantação do Exame Nacional de Cursos e/ou, dependendo do ano em que são publicados, da sistemática de avaliação implantada no Brasil com a edição da Lei que instituiu o Sistema Nacional de Avaliação da Educação Superior. O terceiro momento remete à discussão acerca dos rankings para uma dimensão global, internacional, uma vez que eles vêm sendo apontados como elementos diretamente relacionados à emergência da chamada universidade de classe mundial. São estudos publicados a partir do final da década de 2010, que parecem constituir uma nova vertente de pesquisa sobre o fenômeno dos ranqueamentos que vêm ganhando corpo e consistência nos últimos anos.

Notas explicativas

'Adota-se a expressão rankings acadêmicos, que engloba a diversidade de atividades e funções relacionadas
com o mundo universitário. Além de envolver o ranqueamento de Instituições de Ensino Superior (IES),
permite tomar como referências outros indicadores mais específicos, como cursos de graduação, cursos de
pós-graduação, grupos e instituições de pesquisa científica, egressos e empregabilidade, transferência de
conhecimento, inovação tecnológica, projeção internacional, entre outros. O termo ranking acadêmico é
também adotado em alguns estudos acadêmico-científicos (BERNARDINO; MARQUES, 2010) e consta
do nome de alguns rankings internacionais, como o famoso ranking Shangai, Academic Ranking of World
Universities (ARWU), publicado pela Universidade de Shanghai Jiao Tong.
${ }^{2}$ Como afirma Nóbrega-Therrien e Therrien (2014, p. 7), os trabalhos denominados "estado da questão"
procuram "[...] levar o pesquisador a registrar, a partir de um rigoroso levantamento bibliográfico, como se
encontra o tema ou o objeto de sua investigação no estado atual da ciência ao seu alcance."
${ }^{3}$ O Instituto de Pesquisas Econômicas, Administrativas e Contábeis de Minas Gerais é uma fundação de
apoio à Faculdade de Ciências Econômicas (Face) da Universidade Federal de Minas Gerais.

\section{REFERÊNCIAS}

AFONSO, A. J. Estado, mercado, comunidade e avaliação: esboço para uma rearticulação crítica. Educação \& Sociedade, Campinas, v. 20, n. 69, dez. 1999.

AFONSO, A. J. Mudanças no Estado-avaliador: comparativismo internacional e teoria da modernização revisitada. Revista Brasileira de Educação, Rio de Janeiro, v. 18 , n. 53, jun. 2013. 
ANDRADE, E. de C. Rankings em educação: tipos, problemas, informações e mudanças. Estudos Econômicos, São Paulo, v. 41, n. 2, jun. 2011.

BALL, S. J. Reformar escolas/reformar professores e os terrores da performatividade. Revista Portuguesa de Educação, v. 15, n. 2, p. 3-23, 2002.

BARREYRO, G. B. De exames, rankings e mídia. Avaliação (Campinas), Sorocaba, v. 13, n. 3, nov. 2008.

BARROSO, J. O Estado, a educação e a regulação das políticas públicas. Educação \& Sociedade, Campinas, v. 26, n. 92, out. 2005.

BARROSO, J. Organização e regulação dos ensinos básico e secundário, em Portugal: sentidos de uma evolução. Educação \& Sociedade, Campinas, v. 24, n. 82, abr. 2003.

BRITO, M. R. F. de. O SINAES e o ENADE: da concepção à implantação. Avaliação (Campinas), Sorocaba, v. 13, n. 3, nov. 2008.

CALDERÓN, A. I.; POLTRONIERI, H.; BORGES, R. M. Os rankings na educação superior brasileira: políticas de governo ou de estado? Ensaio: Avalição e Políticas Públicas em Educação, Rio de Janeiro, v. 19, n. 73, dez. 2011.

DIAS SOBRINHO, J. Avaliação ética e política em função da educação como direito público ou como mercadoria? Educação \& Sociedade, Campinas, v. 25, n. 88, out. 2004.

DIAS SOBRINHO, J. Avaliação e transformações da educação superior brasileira (1995-2009): do provão ao Sinaes. Avaliação (Campinas), Sorocaba, v. 15, n. 1,2010 .

DIAS SOBRINHO, J. Qualidade, avaliação: do SINAES a índices. Avaliação (Campinas), Sorocaba, v. 13, n. 3, nov. 2008.

DURHAM, E. R. A política educacional do Governo Fernando Henrique Cardoso: uma visão comparada. Novos Estudos - CEBRAP, São Paulo, n. 88, dez. 2010.

GOUVEIA, A. B. et al. Trajetória da Avaliação da Educação Superior no Brasil: singularidades e contradições (1983-2004). Estudos em Avaliação Educacional, São Paulo, v. 16, n. 31, jun. 2005.

LEITE, D. Ameaças pós-rankings, sobrevivência das CPAs e da autoavaliação. Avaliação, Campinas; Sorocaba, SP, v.13, n. 3, p. 833-840, nov. 2008. 
LIMA, L. C.; AZEVEDO, M. L. N. de; CATANI, A. M. O processo de Bolonha, a avaliação da educação superior e algumas considerações sobre a Universidade Nova. Avaliação (Campinas), Sorocaba, v. 13, n. 1, mar. 2008.

LIMANA, A. Desfazendo mitos: o que estão fazendo com o SINAES? Avaliação (Campinas), Sorocaba, v. 13, n. 3, nov. 2008.

LOPEZ SEGRERA, F. Tendencias de la educación superior en el mundo y en América Latina y el Caribe. Avaliação (Campinas), Sorocaba, v. 13, n. 2, jun. 2008.

LEITE, D. Ameaças pós-rankings, sobrevivência das CPAs e da auto-avaliação. Avaliação, Campinas; Sorocaba, SP, v.13, n. 3, p. 833-840, nov. 2008.

MENEGHEL, S. M.; ROBL, F.; SILVA, T. T. F. da. A relação entre avaliação e regulação na educação superior: elementos para o debate. Educar em Revista, Curitiba, n. 28 , dez. 2006.

MOURA, B. A.; MOURA, L. B. A. Ranqueamento de universidades: reflexões acerca da construção de reconhecimento institucional. Acta Scientiarum. Education, Maringá, v. 35, n. 2, Dec. 2013.

ORDORIKA, I.; GÓMEZ, R. R. El ranking Times en el mercado del prestigio universitario. Perfiles Educativos, v. 32, n. 129, p. 8-22, 2010.

POLIDORI, M. M. Políticas de avaliação da educação superior brasileira: Provão, SINAES, IDD, CPC, IGC e... outros índices. Avaliação (Campinas), Sorocaba, v. 14, n. 2, jul. 2009.

ROTHEN, J. C.; BARREYRO, G. B. Avaliação da educação superior no segundo governo Lula: "provão II" ou a reedição de velhas práticas? Educação \& Sociedade, Campinas, v. 32, n. 114, mar. 2011.

ROTHEN, J. C.; SCHULZ, A. SINAES: do documento original à legislação. Revista Diálogo Educacional, Curitiba, v. 7, n. 21, ago. 2007.

SCHWARTZMAN, J. Dificuldades e possibilidades de se construir um ranking para as universidades brasileiras. Ensaio: Avalição e Políticas Públicas em Educação, Rio de Janeiro, v. 3, n. 6, jan. 1995.

SCHWARTZMAN, J.; OLIVEIRA JÚNIOR, M. de. "Ranking” IPEAD/UFMG e Exame Nacional de Cursos: uma comparação. Ensaio: Avaliação e Políticas Públicas em Educação, Rio de Janeiro, v. 5, n. 16, jul. 1997.

SGUISSARDI, V. Universidade pública estatal: Entre o público e o privado/mercado. Educação \& Sociedade, Campinas, v. 26, n. 90, p. 191-222, jan./abr. 2005. 
SOUZA, S. Z. L. de; OLIVEIRA, R. P. de. Políticas de avaliação da educação e quase mercado no Brasil. Educação \& Sociedade, Campinas, v. 24, n. 84, set. 2003.

THERY, H. Classificações de universidades mundiais, "Xangai" e outras. Estudos Avançados, São Paulo, v. 24, n. 70, 2010.

Recebido em: 21 de janeiro de 2015 Aceito em: 28 de fevereiro de 2015 